\title{
COVID-19 Pulmonary Failure and Extracorporeal Membrane Oxygenation: First Experience from Three European Extracorporeal Membrane Oxygenation Centers
}

\author{
Charles Abraham Yankah ${ }^{1,2(0)}$ Richard Trimlett $^{3}$ Elena Sandoval ${ }^{4}$ Christopher Lotz $^{5}$ \\ Stephane Ledot ${ }^{6}$ Jose Luis Pomar ${ }^{4,7}$ Susanna Price ${ }^{8}$ Patrick Meybohm ${ }^{5}$
}

${ }^{1}$ Department of Thoracic and Cardiovascular Surgery, Deutsches Herzzentrum Berlin/Charité, Berlin, Germany

2 Department of International Relations, Pan-African Society for Cardiothoracic Surgery, Berlin, Germany

${ }^{3}$ Department of Cardiac Surgery, Royal Brompton Hospital, London, United Kingdom of Great Britain and Northern Ireland

${ }^{4}$ Department of Cardiac Surgery, Clinic Barcelona Hospital University, Barcelona, Spain

${ }^{5}$ Department of Anaesthesiology and Intensive Care Medicine,

University Hospital Wurzburg, Wurzburg, Bayern, Germany

${ }^{6}$ Department of Intensive Care Medicine, Royal Brompton and Harefield NHS Trust, London, United Kingdom of Great Britain and Northern Ireland

7 Department of Cardiac Surgery, Barnaclinic, Barcelona, Spain

${ }^{8}$ Department of Cardiology and Intensive Care, Royal Brompton and Harefield NHS Trust, London, United Kingdom of Great Britain and Northern Ireland
Address for correspondence Charles Abraham Yankah, MD, PhD, Department of Thoracic and Cardiovascular Surgery, Deutsches Herzzentrum Berlin/Charité, Augustenburger Platz 1, Berlin 13353, Germany (e-mail: cyankah@web.de; yankah@dhzb.de).

Thorac Cardiovasc Surg 2021;69:259-262.

\begin{abstract}
Keywords

- acute respiratory failure

- C-ARDS

- advanced life support

- VV ECMO, VA ECM

- pulmonary thrombosis (microthrombosis, systemic microthrombosis, thrombolysis)

On April 17, 2020, a coronavirus disease 2019 (COVID-19) webinar was held by selected international experts in the field of intensive care and specialized respiratory ECMO centers from Germany, Italy, Spain, and the United Kingdom, which was hosted by the German Heart Centre Berlin/Charité. The experts shared their experience about the treatment of 42 patients with severe acute respiratory failure requiring venovenous extracorporeal membrane oxygenation (VV-ECMO). Patients were predominantly male (male-to-female ratio: 3:1), with a mean age of 51 years (range: $25-73$ years). VV-ECMO support was indicated in $30 \%$ of the ventilated COVID-19 patients. The mean time requiring mechanical ventilation was 16.5 days, with a mean duration of ECMO support of 10.6 days. At the time of the webinar, a total of 17 patients had already been decannulated from ECMO, whereas six died with multiorgan failure. 18 patients remained on ECMO, with their final outcomes unknown at the time of the webinar. Hospital mortality was $25.6 \%$ (as of April 17, 2020). In this respect, VV-ECMO, provided by expert centers, is a recognized and validated mode of advanced life-support during the recent COVID-19 pandemic with good outcomes.
\end{abstract}

received

June 17, 2020

accepted after revision

September 17, 2020

published online

November 13, 2020 (c) 2020. Thieme. All rights reserved.

Georg Thieme Verlag KG,

Rüdigerstraße 14,

70469 Stuttgart, Germany
DOI https://doi.org/

10.1055/s-0040-1719156. ISSN 0171-6425. 


\section{Introduction}

The outbreak of coronavirus disease 2019 (COVID-19) was first reported in December 2019 in the central Chinese city of Wuhan, which was characterized by acute respiratory distress syndrome (ARDS) caused by severe or fatal pneumonia. ${ }^{1}$ Initial clinical reports showed mortality of $49 \%$ or more among patients with coexisting diseases who developed severe COVID-19 ARDS (C-ARDS) refractory to maximal therapy. ${ }^{1}$ A venovenous extracorporeal membrane oxygenation (VV-ECMO) can be used to rescue eligible patients. ${ }^{2-4}$

To date, refractory C-ARDS has claimed many lives worldwide, with more than 434,793 deaths among 7,973,302 confirmed cases (Johns Hopkins University in Baltimore, June 15,2020$){ }^{5}$ This has challenged health care providers to strengthen their strategic response and develop more capacity for COVID-19 critical care including VV-ECMO services to eligible patients at centers of excellence. ${ }^{4}$

The World Health Organization (WHO) declared a COVID19 pandemic on March 11,2020. In the preliminary guidelines for the management of COVID-19, the WHO recommended that "In settings with access to expertise in extracorporeal life support (ECLS), consider referral of patients with refractory hypoxemia despite lung protective ventilation." This was supported in a statement from the Extracorporeal Life Support Organization (ELSO), stating "If the hospital feels that ECMO can be safely provided, then it should be offered to patients with a good prognosis with the use of ECMO."

The first European COVID-19 webinar on "Acute CardioPulmonary Failure" was held on April 17, 2020. The experiences of the frontline critical care physicians from leading European VV-ECMO centers with the use of VV-ECMO in COVID-19 were shared. Additional discussions were held regarding the use of COVID-19 convalescent plasma antibody for treating patients, as well as potential future antiviral strategies, for example, the antiviral protease inhibitor remdesivir. The management of COVID-19 patients with the introduction of early application of immune-modulatory therapy to inhibit the life-threatening cytokine storms, thus preventing multiorgan failure, was also discussed. ${ }^{8-10}$
The decision to implement VV-ECMO, however, remains challenging, particularly where resources are limited due to excessive demand such as a pandemic. This is further compounded when a novel pathogen is encountered, with uncertain patterns of progression, recovery and mortality, and uncertain efficacy of conventional therapies such as VVECMO. Ultimately, the decision to use scarce resources to support individual patients in crisis can only be guided by the collection and publication of data.

\section{Methods}

Experts from Germany, Italy, Spain, and United Kingdom held a webinar organized by the German Heart Centre Berlin in collaboration with the Department of Anaesthesiology and Intensive Care Medicine, Charité - University of Medicine Berlin on April 17, 2020, where the local experience with the treatment of COVID-19 patients with severe acute respiratory failure requiring VV-ECMO support was shared and discussed. Following this, a retrospective anonymous review of contemporaneous non-ECMO COVID-19 patients requiring ventilation (but not requiring VV-ECMO) in these centers was conducted.

\section{Results}

Until April 17, 2020, a total of 140 patients ( 43 females and 97 males; average age: 59 years) with COVID-19 requiring mechanical ventilation were admitted to the three participating centers ( $\mathbf{- T a b l e ~} \mathbf{1}$ ). The immune response was characterized by the following laboratory median values: lymphocytopenia ( 0.87 [normal: $1,000-4,800$ in $1 \mu \mathrm{L}$ ]), high levels of C-reactive protein (CRP) $(21.75 \mathrm{mg} / \mathrm{L}$ [normal: $<5-10 \mathrm{mg} / \mathrm{L}])$, interleukin-6 (IL-6) (213 [normal: 0-16.4 pg/mL]), and D-dimer (2.5 [normal: $0.4 \mu \mathrm{g} / \mathrm{mL}$ ]). Some of the patients supported with VVECMO received immune-modulatory therapy with, anti-IL receptor antibody, tocilizumab. All patients were systemically anticoagulated unless contra-indicated.

The mean duration of mechanical ventilation was 16.5 days and that of VV-ECMO support was 10.6 days. Gender distribution of ECMO patients was as follows - female/male: 12/30

Table 1 Summarized data from three European Specialist ECMO Centers, Barcelona, London, Wurzburg, until the webinar on April 17, 2020

\begin{tabular}{|c|c|c|c|c|c|c|c|}
\hline ECMO center & $\begin{array}{l}\text { On ventilation } \\
\text { (COVID-19. } \\
\text { Total \& F/M } \\
n\end{array}$ & $\begin{array}{l}\text { On ventilation } \\
\text { Average } \\
\text { age } \mathrm{F} / \mathrm{M} \\
\text { Range } \\
\text { (years) }\end{array}$ & $\begin{array}{l}\text { ECMO } \\
\text { COVID-19 } \\
\text { Total \& F/M } \\
n\end{array}$ & $\begin{array}{l}\text { ECMO Average } \\
\text { age F/M } \\
\text { Range (years) }\end{array}$ & $\begin{array}{l}\text { ECMO } \\
\text { weaned } \\
\text { by April } \\
17,2020\end{array}$ & $\begin{array}{l}\text { ECMO } \\
\text { duration } \\
\text { (days) }\end{array}$ & $\begin{array}{l}\text { 30-D survival } \\
\text { ECMO to } \\
\text { April 17, } 2020\end{array}$ \\
\hline $\begin{array}{l}\text { Hospital Clinic, } \\
\text { University Barcelona } \\
\text { (Spain) }\end{array}$ & $21: 5 / 16$ & $\begin{array}{l}64 / 86 \\
25-79\end{array}$ & 5: $1 / 4$ & $\begin{array}{l}73 / 51.4 \\
25-73\end{array}$ & 4 & 8 & $80 \%$ \\
\hline $\begin{array}{l}\text { Royal Brompton } \\
\text { Hospital London (UK) }\end{array}$ & $93: 27 / 66$ & $\begin{array}{l}51 / 54 \\
21-85\end{array}$ & 29: $7 / 22$ & $\begin{array}{l}46 / 46 \\
29-64\end{array}$ & 9 & 10.6 & $93.1 \%$ \\
\hline $\begin{array}{l}\text { University Hospital } \\
\text { Wurzburg (Germany) }\end{array}$ & $26: 11 / 15$ & $\begin{array}{l}63.6 \\
36-83\end{array}$ & $8: 4 / 4$ & $\begin{array}{l}55.8 / 53.5 \\
36-69\end{array}$ & 4 & 13.1 & $50 \%$ \\
\hline Total & 140: $43 / 97$ & 59.2: $21-85$ & $42: 12 / 30$ & $\begin{array}{l}58.3 / 50.3: \\
25-73\end{array}$ & 17 & 10.6 & $74.4 \%$ \\
\hline
\end{tabular}

Abbreviations: COVID-19, coronavirus disease 2019; ECMO, extracorporeal membrane oxygenation. 


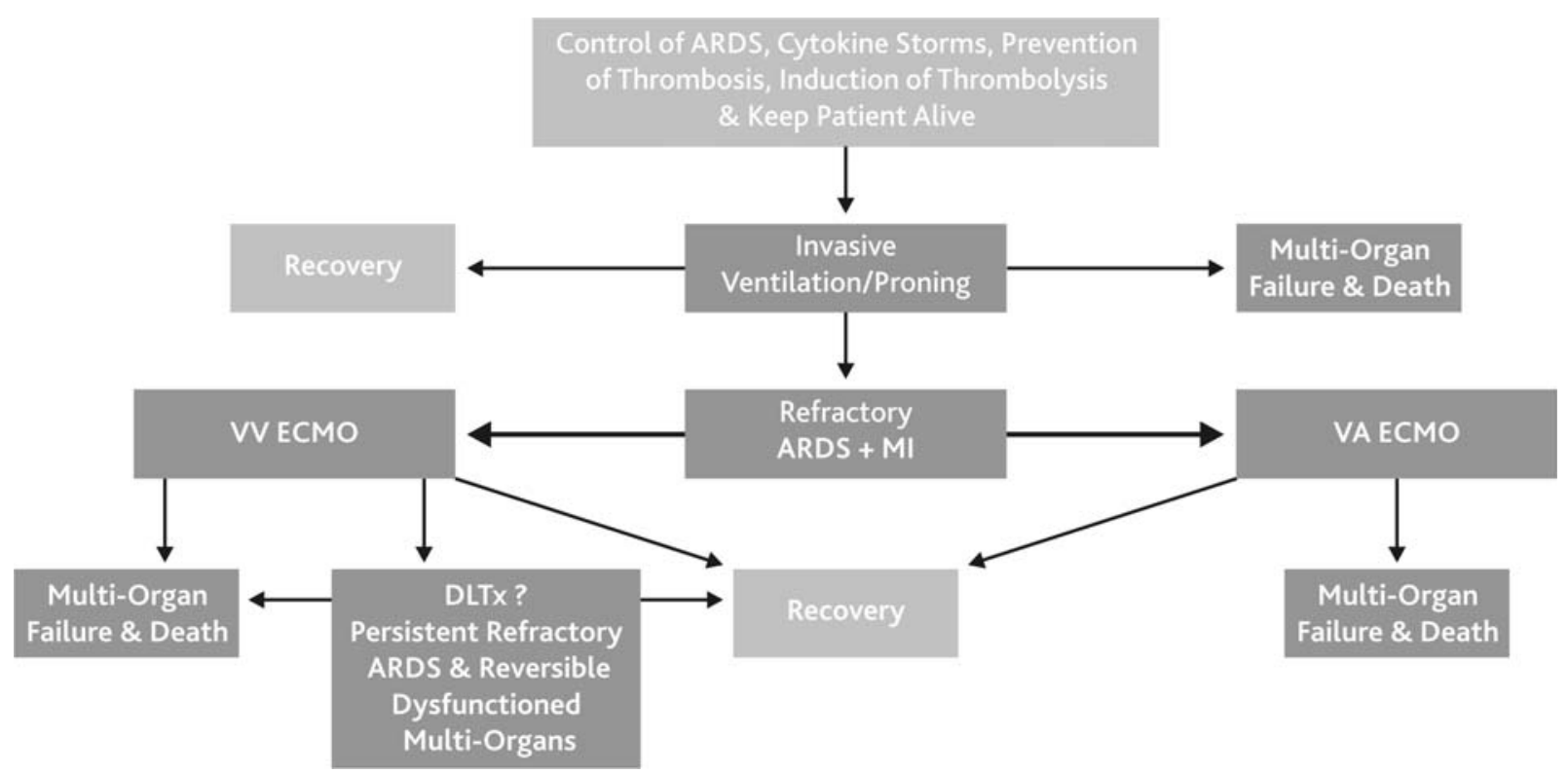

Fig. 1 Goals of cardiorespiratory support in COVID-19 patients with ARDS. ARDS, acute respiratory distress syndrome; COVID-19, coronavirus disease 2019; DLTx, double lung transplantation; ECMO, extracorporeal membrane oxygenation; MI, myocardial infarction; VA, veno-arterial; $\mathrm{VV}$, venovenous.

$(n=42)$ and the age distribution was $58 / 50$ years ( - Table 1$)$. At the time of the webinar, 17 patients had been decannulated from ECMO, and 7 (25.6\%) had died with multiorgan failure. Eighteen patients remained on ECMO, with their final outcomes unknown at the time of the webinar. Thirty-day patient survival (as of April 17, 2020) was $74.4 \%$ (-Table 1 ).

\section{Discussion}

The unprecedented global COVID-19 pandemic with propensity to cause ARDS and high rate of death on invasive ventilation has demanded rescue VV-ECMO therapy in moderate- to high-risk patients. Depending on the individual patient pathophysiology, vascular status, cardiac function, local expertise, and local resources, the optimal ECMO strategy needs to be considered. ${ }^{11-13}$

Mortality in critically ill COVID-19 patients ranges between 24 and $68 \%{ }^{14,15}$ The clinical course and outcome of COVID-19 patients were influenced by age, gender, body mass index, and coexisting pathology. Comorbidities were important predictors of increased mortality and were found in $74 \%$ of critically ill COVID-19 patients. ${ }^{16,17}$ The high mortality rate in critically ill COVID-19 patients should prompt early evaluation of at-risk patients, including early measurement of biomarkers of pulmonary injury and cardiothoracic imaging. ${ }^{1,3,4,10,18}$ The pathology of the associated pulmonary injury described includes alveolar damage, hypersecretion and plugging, vasculitis, and extensive systemic microthrombosis. The immune response is often characterized by lymphocytopenia, high levels of CRP, cytokines, IL-6, and D-dimer. ${ }^{8-10,18}$ Elevated D-dimer levels $(>1 \mathrm{~g} / \mathrm{L})$, IL-6, and troponin are associated with in-hospital death, ${ }^{10,19}$ Cytokine storms activate the coagulation pathway and vascular endothelial cells, which also inhibit myocardial cell function. ${ }^{10}$ IL-6 blocking therapy with anti-IL-6 receptor (tocilizumab) may be a novel therapeutic strategy for controlling cytokine storm and prevention of multiorgan failure in COVID19 infection. $^{20}$ Selective filtration of macrophages using the "CytoSorb technique" is also under investigation but requires validation. ${ }^{21}$

Where conventional critical care interventions, including lung-protective ventilatory strategies and proning, are insufficient, preliminary data suggest that VV-ECMO may improve survival rates. ${ }^{17}$ Participating experts from the three ${ }^{3}$ centers reported their local experience with a cumulatively low inhospital mortality rate (30 days) of $25.6 \%$ (as of April 17, 2020).

These promising results from expert centers and the algorithm in - Fig. 1 may offer some additional guidance for those considering the role of VV-ECMO in the ongoing pandemic, including its potential role in any future pandemic surges. ${ }^{22}$

It is well recognized that higher volume ECMO centers have superior outcomes when compared with intermittent/ low-volume providers. The excellent outcomes discussed in this webinar further underscore the role of the "expert center." Any wider expansion considered in future should focus on developing additional capacity in those centers with existing programs and expertise. Indeed, the ELSO recommends against starting new ECMO centers for the sole purpose of treating patients with COVID-19. ${ }^{7}$ Finally, the international collaboration and rapid sharing of expertise through the expanded use of technology and case-based discussion should be considered as a model for the future.

Conflict of Interest

None declared.

\section{Acknowledgments}

We are grateful to Prof. Dr. Claudia Spies, Director, Prof. Dr. Roland Francis, Deputy Director, Dr. Bjoern Weiss, Consultant, Department of Anaesthesiology and Intensive Care Medicine (CVK/CCM), Charité - University of Medicine 
Berlin, Germany, and Prof. Dr. Volkmar Falk, Director, German Heart Centre Berlin, Head, Department of Cardiothoracic and Vascular Surgery, German Heart Centre Berlin, and Charité - University of Medicine Berlin, for supporting the program, as well as our invited speakers, guests, and discussants: Mr. Ulrich Rosendahl, Consultant Cardiac Surgeon, Clinical Lead Aortic Unit, Royal Brompton \& Harefield NHS Foundation Trust, Senior Clinical Lecturer, Imperial College and Royal Brompton Hospital, London, Prof. Dr. Christoph Starck, Senior Consultant, Department of Cardiothoracic and Vascular Surgery, German Heart Centre Berlin, Dr. Carlos Mestres, Snr. Consultant, Department. of Cardiothoracic Surgery, University Hospital, Zuerich, Switzerland, Prof. Dr. Ottavio Alfieri, Professor of Cardiac Surgery, Dr. Mara Scandroglio, Dr. Evgeny Fominsky, St. Raffaele University Hospital Milano, Italy, Prof. Dr. Christian Hagl, Director, Department. of Cardiothoracic Surgery, University of Munich, Germany, and Prof. Dr. Paolo Brenner, University of Munich, Germany.

We thank our technical supporters at the German Heart Centre Berlin Service Ltd, Mr. Philipp Krueger, ICT Manager, for providing excellent ICT support for the webinar series and Mr. Helge Haselbach, artist, for the graphic design work.

\section{References}

1 Wu Z, McGoogan JM. Characteristics of important lessons from the coronavirus disease 2019 (COVID-19) outbreak in China: summary of a report of 72314 cases from the Chinese Center for Disease Control and Prevention. JAMA 2020;323(13):1239-1242

2 Ramanathan K, Antognini D, Combes A, et al. Planning and provision of ECMO services for severe ARDS during the COVID19 pandemic and other outbreaks of emerging infectious diseases. Lancet Respir Med 2020;8(05):518-526

3 Zeng Y, Cai Z, Xianyu Y, Yang BX, Song T, Yan Q. Prognosis when using extracorporeal membrane oxygenation (ECMO) for critically ill COVID-19 patients in China: a retrospective case series. Crit Care 2020;24(01):148

4 MacLaren G, Fisher D, Brodie D. Preparing for the most critically ill patients with COVID-19: the potential role of extracorporeal membrane oxygenation. JAMA 2020;323(13):1245-1246

5 Johns Hopkins Coronavirus Resource Centre.COVID-19 Map. https://coronavirus.jhu.edu/map.html. Accessed June 15, 2020

6 World Health Organization. Clinical management of severe acute respiratory infection when novel coronavirus (2019-nCoV) infection is suspected: interim guidance. https://apps.who.int/iris/bitstream/handle/10665/330854/WHO-nCoV-Clinical-2020.2-eng. pdf? sequence $=1$ \&isAllowed $=\mathrm{yWHO} / \mathrm{nCoV} /$ Clinical/2020.2. Accessed May 19, 2020

7 Extracorporeal Life Support Organization. ELSO Guidance document: ECMO for COVID-19 Patients with severe cardiopulmonary failure. https://www.elso.org/Portals/0/Files/pdf/ECMO\%20for\% 20COVID\%2019\%20Guidance\%20Document.Final\%2003.24.2020. pdf. Accessed May 19, 2020
8 Luo P, Liu Y, Qiu L, Liu X, Liu D, Li J. Tocilizumab treatment in COVID-19: A single center experience. J Med Virol 2020;92(07): 814-818

9 Tanaka T, Narazaki M, Kishimoto T. Immunotherapeutic implications of IL-6 blockade for cytokine storm. Immunotherapy 2016;8 (08):959-970

10 Beck DL. Cardiac injury common in COVID-19, predicts mortality. https://www.medscape.com/viewarticle/927505. Accessed May 19, 2020

11 Zakhary B, Shekar K, Diaz R, et al; Extracorporeal Life Support Organization (ELSO) ECMOed Taskforce. Position paper on global extracorporeal membrane oxygenation education and educational agenda for the future: a statement from the Extracorporeal Life Support Organization ECMOed Taskforce. Crit Care Med 2020;48 (03):406-414

12 Abrams D, Pham T, Burns KEA, et al; International ECMO Network (ECMONet). Practice patterns and ethical considerations in the management of venovenous extracorporeal membrane oxygenation patients: an international survey. Crit Care Med 2019;47 (10):1346-1355

13 Combes A, Hajage D, Capellier G, et al; EOLIA Trial Group, REVA, and ECMONet. Extracorporeal membrane oxygenation for severe acute respiratory distress syndrome. N Engl J Med 2018;378(21): 1965-1975

14 Munshi L, Walkey A, Goligher E, Pham T, Uleryk EM, Fan E. Venovenous extracorporeal membrane oxygenation for acute respiratory distress syndrome: a systematic review and metaanalysis. Lancet Respir Med 2019;7(02):163-172

15 EL PAIS. Why is the coronavirus killing nearly twice as many men as women in Spain? https://english.elpais.com/society/2020-0325/why-is-the-coronavirus-killing-nearly-twice-as-many-menas-women-in-spain.html. Accessed May 19, 2020

16 Intensive Care National Audit \& Research Centre (ICNARC) report on COVID-19 in critical care. Report on 8250 patients critically ill with COVID-19 https://www.icnarc.org/Reporting. Accessed May 19, 2020

17 Guervilly C, Prud'homme E, Pauly V, et al. Prone positioning and extracorporeal membrane oxygenation for severe acute respiratory distress syndrome: time for a randomized trial? Intensive Care Med 2019;45(07):1040-1042

18 Khan IH, Savarimuthu S, Leung MST, Harky A. The need to manage the risk of thromboembolism in COVID-19 patients. J Vasc Surg 2020;72(03):799-804

$19 \mathrm{Wu}$ C, Chen X, Cai Y, et al. Risk factors associated with acute respiratory distress syndrome and death in patients with coronavirus disease 2019 pneumonia in Wuhan, China. JAMA Intern Med 2020;180(07):934-943

20 Gibson PG, Qin L, Puah S. COVID-19 ARDS: clinical features and differences to "usual" pre-COVID ARDS. https://www.mja.com.au/ journal/2020/covid-19-ards-clinical-features-and-differences-usual-pre-covid-ards. Accessed May 192020

21 Morris C, Gray L, Giovannelli M. Early report: the use of Cytosorb ${ }^{\mathrm{TM}}$ haemabsorption column as an adjunct in managing severe sepsis: initial experiences, review and recommendations. J Intensive Care Soc 2015; 16(03):257-264

22 Zou S, Liu K. Dying coronavirus patients saved by lung transplants. https://www.chinadaily.com.cn/a/202005/13/WS5ebb394fa310a8b2 4115538c.html. Accessed June 12, 2020 